GEOgraphia

Niterói, Universidade Federal Fluminense

ISSN 15177793 (eletrônico)

Vol.19, №40, 2017: mai./ago

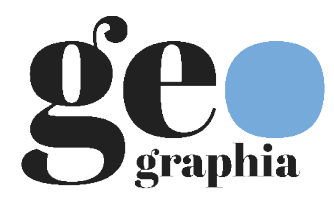

Dossiê Doreen Massey

\section{LUGARES QUE FAZEM DIFERENÇA: ENCONTROS COM DOREEN MASSEY*}

Rogério Haesbaert**

Universidade Federal Fluminense
Este texto pretende elaborar um diálogo, ao mesmo tempo intelectual e afetivo, com a geógrafa e amiga Doreen Massey, que nos deixou há pouco mais de um ano. É, assim, igualmente, uma forma de tributo, acadêmico e pessoal, a uma das maiores geógrafas do nosso tempo. Reflito a partir de inspirações que ela sugere em distintos momentos de sua rica trajetória intelectual e que, entrecruzando lugares, permitem confrontar e, de algum modo, recompor em outras bases as nossas diferenças. Gostaria de, sempre que possível, mesclar considerações em nível pessoal de minha relação afetiva com Doreen e reflexões sobre o papel do espaço na construção da diferença e da multiplicidade, considerando o quanto esse aspecto permeava nossos trabalhos, abrindo perspectivas para diálogos enriquecedores.

Em uma era de "tempos virtuais" Doreen ainda preferia a escrita no papel e era uma entusiasta dos contatos face a face. Talvez por isso tenha exclamado de forma tão enfática "você é real!" quando me viu pela primeira vez na plataforma da estação Euston, em Londres, rumo à Open University, em Milton Keynes, depois de vários contatos feitos apenas pela internet. Doreen resistiu como poucos ao poder da efemeridade dos contatos virtuais e instantâneos. Talvez por isso não tenha dado tanta importância, em seu debate sobre o espaço, às relações à distância e ao ciberespaço. Sempre me identifiquei muito com sua valorização dos vínculos diretos, de proximidade. Provavelmente sua fragilidade física, com uma enfermidade que debilitava os ossos e que the infligia dores constantes, tornou-a ainda mais sensível ao contato direto, ao "próximo". Várias fraturas muito sérias ocorreram ao longo de sua vida, em pequenas quedas no metrô ou no trem. Isso, sem dúvida, aguçava sua sensibilidade e sua percepção do espaço.

Eu sempre lamentava sua demora na resposta de e-mails, pois ela, que resistia ao uso do computador, dependia de uma secretária (secretárias, aliás, que muito prezava). Por outro lado, nunca reclamei dos seus belos cartões de Natal mesmo que, no Brasil, chegassem sempre atrasados. Doreen ainda caprichava nos recados desenhados a mão e que, assim, densificavam a superfície lisa do espaço branco dos papéis - como se também neles quisesse questionar a visão de um espaço absoluto, liso, em superfície. Numa paródia ao icônico "Ceci n'est pas une pipe", do pintor Magritte, ela escreveria enfaticamente na legenda de um mapa em seu livro "Pelo Espaço": "Isto não é o espaço".

Gostaria de destacar, de início, o engajamento de Doreen com todo o leque de perspectivas conceituais que vai das categorias cotidianas, da prática, às categorias analíticas, intelectuais (que incluem também o que podemos denominar de categorias pedagógicas), passando pelo caráter político-normativo - o qual não separava nem mesmo de seus comportamentos mais pessoais. Um dos maiores méritos do trabalho de Doreen é sem dúvida sua habilidade em construir reflexões teóricas a partir de fatos simples, cotidianos, como aqueles ligados a seus amigos ou a sua família (como em suas reflexões sobre o tempo-espaço a partir da expectativa não atendida de um bolo "tradicional" feito

\footnotetext{
* Este texto é uma versão ampliada da apresentação feita em homenagem a Doreen Massey na mesa "In honour of Doreen Massey", realizada durante o encontro anual da AAG (Association of American Geographers) em Boston (EUA), abril de 2017, e organizada por Jamie Peck, Victoria Lawson e Erica Schoenberger, a quem agradeço pelo convite.

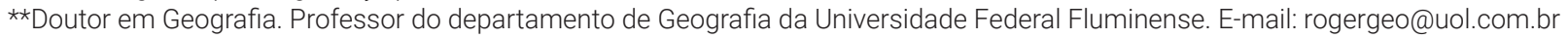


por sua mãe). Isso tornava sua linguagem muito mais comunicativa, ampliando o alcance de seu pensamento.

Nos múltiplos veículos em que difundia suas ideias (incluindo programas de rádio e televisão) e através do diálogo com diversas áreas de conhecimento (da Arte à Economia), a clareza e a aparente simplicidade não comprometiam o rigor e a profundidade de suas proposições. Essas características estão vinculadas ao importante papel pedagógico que também desenvolveu, preparando valioso material didático para os estudantes da Open University, muitos deles pertencentes às classes populares e dos quais muito se orgulhava'. Sua identificação com o caráter democrático da instituição e a qualidade de seu Departamento de Geografia eram sempre enaltecidos. Doreen era uma apaixonada por tudo que fazia, inclusive - ou talvez mais ainda - como torcedora do Liverpool. Além de, sempre que possível, assistir pessoalmente aos jogos, era capaz de largar tudo (no intervalo de um congresso como o da ANPEGE, em 2005, por exemplo), para acompanhar uma partida de seu time.

Doreen era de uma coerência visceral entre o mundo que pensava e o que praticava, entre o mundo da reflexão teórica e a esfera da ação política. Às vezes até de forma meio teimosa, como no tempo que levou para voltar a visitar os Estados Unidos onde havia realizado seus estudos de pós-graduação em Regional Science. Só voltou quando recebeu uma grande homenagem da Associação de Geógrafos Americanos. Até da recusa a beber Coca-Cola ela fazia mais uma atitude simbólica de protesto contra o Grande Império.

Doreen, em mais uma prova de suas posições alternativas, nunca recebeu formalmente o título de Doutor e se recusava a lecionar em Oxford, que considerava uma instituição elitista - com conhecimento de causa, pois ganhou uma bolsa para fazer sua graduação ali. No nosso último encontro, em julho de 2015 , ela afirmou que o que realmente almejava priorizar, agora aposentada, era o fazer político. Polêmica em alguns posicionamentos políticos, tivemos discussões acaloradas no que se refere a seu apoio irrestrito ao governo Chávez, na Venezuela. Mas, temos de convir, como não defender uma política que passou a usar diretamente uma de suas concepções mais difundidas, a de geometrias de poder do espaçotempo? Ela própria se surpreenderia muito quando, ao chegar pela primeira vez para um debate com intelectuais e políticos venezuelanos, deparou-se com um outdoor que explícitava a busca por uma "nova geometria de poder".

Era extremamente preocupada com a eficácia política de nossos conceitos. Nada lhe poderia ser mais avesso do

${ }^{1} \mathrm{O}$ expressivo papel da dimensão pedagógica de seu trabalho não foi até agora devidamente analisado. Acredito que uma lacuna importante, nesse sentido, será preenchida com a pesquisa de pós-doutorado de Ana Angelita Rocha, que também organiza e participa deste dossiê. que um pensamento acadêmico abstrato, sem vinculação direta com a realidade vivida e com o compromisso pela mudança em prol dos grupos subalternos. Seu apoio a diversas políticas do Partido Trabalhista inglês é bem conhecido. Nem por isso deixou de formular densas reflexões teóricas, saltando com capacidade ímpar de uma descrição aparentemente banal da vida cotidiana para um conceito mais complexamente elaborado.

Inovadora, não deixava de, ao mesmo tempo, adotar e criticar correntes consolidadas, como o marxismo dos anos 1980, conforme retratado em seu Spatial Divisions of Labour (para um balanço das repercussões deste livro, publicado em 1984 e com segunda edição em 1995, v. Phelps, 2008, eCallard, 2004). Também trouxe importantes contribuições ao debate regional, em textos como In what sense a regional problem (de 1979) ou "Regionalismo: alguns problemas atuais" (Massey, 1981) e na obra coletiva Rethinking the Region (Massey et al., 1998). Nos anos 1990, foi uma das pioneiras na introdução do debate sobre gênero na Geografia², questionando David Harvey e Edward Soja por terem negligenciado o papel do gênero e da etnia em suas obras sobre pós-modernidade e, no caso de Harvey, em sua concepção de compressão espaço-tempo (Massey, 1991a).

Foi ainda uma das precursoras do pensamento pós e descolonial na Geografia, a começar pela forma sempre respeitosa com que tratava o pensamento e as práticas de países "periféricos" como quando de sua estada entre os sandinistas da Nicarágua, nos anos 1970, e na África do Sul, para debater com planejadores locais. Ela fazia questão de afırmar que tinha muito a aprender com eles. Doreen recebeu, ainda em vida, importantes obras em sua homenagem, com destaque para Spatial Politics, organizado por Joe Painter e Mike Featherstone (2011) e "Doreen Massey: un sentido global de lugar", organizado por Abel Albet e Núria Benach (2012), e que traz no subtítulo alusão a seu texto mais conhecido (Massey, 1991b).

Através de sua concepção relacional de espaço, Massey definiu lugar como uma imbricação de múltiplas trajetórias, considerando o movimento e a transformação como constituintes fundamentais na construção do espaço. O termo aparentemente simples "trajetória" sintetiza esta dupla constituição espaço-temporal: não é possível definir trajetória sem vincular de maneira indissociável espaço e tempo. Provavelmente não exista melhor expressão, assim, para romper com a dicotomia entre as categorias mestras, espaço e tempo.

Se tomarmos o dicionário e buscarmos o sentido proposto para a palavra, verificaremos que significa "linha descrita ou percorrida por um corpo em movimento",

\footnotetext{
2Sobre sua posição como "geógrafa feminista", mais do que como de uma geógrafa que estuda gênero, ver o artigo de Joseli Silva, neste mesmo dossiê.
} 
do latim "trajectore", "o que atravessa" (Novo Aurélio Dicionário da Língua Portuguesa), "caminho percorrido por um corpo ou partícula em movimento", "ação de percorrer esse trajeto" - trajeto, por sua vez, significando "espaço que é preciso percorrer para ir de um lugar a outro" (Dicionário Houaiss da Língua Portuguesa). Ou seja, trajetória significa ao mesmo tempo o espaço (geográfico) percorrido e o movimento, o percurso (histórico) dessa jornada, totalmente geminados. Assim, a maior ou menor abertura do espaço para a configuração de novas trajetórias - em outros termos, a multiplicidade inerente ao espaço - é condição fundamental para a criação de uma nova história, de um novo tempo.

Trajetória encontra-se intimamente associada, também, com encontro, outro tema recorrente na obra de Doreen e fundamental para a ênfase que ela dá ao espaço como dimensão da multiplicidade e da diferença. Seu conceito de lugar, ao contrário de visões antes dominantes, envolve sobretudo redes, conexões, encontros. E de conexões profundamente marcadas pela materialidade. Doreen, assim, inovou ao condenar as visões que ela denominava "reacionárias" do espaço e do lugar, visto por muitos (como Yu Fu-Tuan) como lócus de estabilidade e segurança. Doreen nunca gostou de lugares assépticos e "seguros". Preferia o desafio do espaço múltiplo onde o Outro sempre reserva uma condição para o inesperado. Seu espaço como emaranhado de trajetórias ela fazia questão de dizer que estava sempre em aberto, sempre carregado de potenciais contingências para a realização de novas e desafiadoras conexões. Por mais impositivo e opressor que possa parecer, o espaço, a multiplicidade de trajetórias que ele comporta acaba sempre abrindo a perspectiva de "outros espaços". Ela não dialogava muito com Foucault, mas não há como não fazer aqui uma analogia com suas heterotopias.

Durante nosso intercâmbio de quase um ano durante o estágio pós-doutoral que desenvolvi sob sua supervisão ficou muito claro o quanto a vinculação do espaço com a diferença e a multiplicidade permeava tanto o seu trabalho, especialmente em relação ao seu sentido global de lugar, numa perspectiva anglo-saxônica, quanto o que eu vinha desenvolvendo em relação aos conceitos de território e multerritorialidade, numa perspectiva latino-americana. Isso abriu a possibilidade de um rico diálogo, iniciado com o livro "O mito da desterritorialização" e a tradução para o português de "Pelo Espaço" e prosseguido depois, de forma mais direta, com o artigo "Do sentido global de lugar à multiterritorialidade"3.

O espaço e o lugar de Doreen eram sempre "espaços outros". Não apenas seu bairro, Kilburn, em Londres, mas também seu "refúgio" de férias no Lake District,

${ }^{3}$ Este artigo foi publicado no livro em homenagem a Doreen, já aqui citado (Painter e Featherstone, 2013) e depois em português como capítulo do livro "Viver no limite" (Haesbaert, 2014) que tive a satisfação de compartilhar com ela e sua irmã Hilary. O Lake District é uma verdadeira paisagem inglesa "heterotópica", pois poucos estrangeiros ouvem falar de uma Inglaterra de lagos e montanhas. Ali também ela (se) encontrava (com) diversos lugares, diversas redes, ainda que estas fossem moldadas mais pela chamada dinâmica da natureza. Ali tivemos um momento único admirando o céu noturno atravessado pelo turbilhão de estrelas da Via Láctea (ausente no céu das grandes metrópoles), buscando o movimento de satélites e lembrando como essas trajetórias também, de alguma forma, acabavam compondo o nosso espaço, o nosso lugar, ao mesmo tempo em que reviviam distantes memórias de nossa infância.

Não esqueço um de nossos passeios em Jericoacoara, para onde fomos descansar depois do encontro da ANPEGE em Fortaleza, em 2005. Em meio a uma jornada de buggie por dunas e lagoas, seu fascínio maior se manifestou em detalhes inusitados, mas bem reveladores de sua busca por movimentos e espaços outros: como quando nos surpreendeu pedindo uma parada para observar a toca de uma coruja na base de uma pequena duna. Observação de pássaros sempre foi um de seus hobbies prediletos. Mais do que o mar, ela se revelou fascinada pelo sertão, pela semi-aridez ímpar da caatinga e histórias como a dos cangaceiros - que ela já conhecia desde que estivera em Pernambuco, nos anos 1980, para realizar um documentário para a emissora britânica BBC (divulgado em 1986).

Ninguém, assim, poderia the questionar por propor uma concepção de lugar "sem natureza". Meio em resposta a críticas como essa foi que desdobrou em seu livro "Pelo Espaço" a concepção de lugar que, mesmo sendo profundamente marcado por traços "naturais", como no "sentido global de lugar" que formulou a partir de seu bairro Iondrino, Kilburn, também era marcado pela dinâmica e pelo encontro de trajetórias, desde a base geológica de placas tectônicas que, há muito tempo, vieram de longe dali, até os pássaros que migram sazonalmente desde o longínquo hemisfério sul. Um dos últimos questionamentos que me fez foi onde estava a natureza na minha concepção de desterritorialização... (de fato a comento, mas para dizer que não se trata exatamente de "poder", mas de "força" - da natureza).

A intuição "antenada" de Doreen nos surpreendia. Como também sua fina ironia, que constantemente nos desafiava. Doreen aliava como poucos amabilidade e provocação. Tornou-se assim uma grande e inesquecível amiga porque não apenas descobrimos mais pontos em comum do que imaginávamos mas também porque ela tinha a incrível capacidade de nos surpreender o tempo todo. Quando tudo parecia transcorrer rumo à mais terna calmaria, Doreen subitamente nos sacudia com uma intervenção ou "sacada" completamente inesperada, 
colocando em xeque nossos mais seguros pressupostos.

Londres, com que Saskia Sassen inaugurou suas "cidades globais" ao lado de Tóquio e Nova York, e que Doreen Massey retratou em livro como "Cidade Mundial" (Massey, 2007), é provavelmente, ao lado da big apple, a urbe etnicamente mais diversificada do mundo. Mas infelizmente trata-se de uma multiplicidade que na maioria das vezes apenas se cruza e, quando admirada, é uma admiração à distância, como representação de um espaço não efetivamente vivido e partilhado. Predominam cruzamentos meramente funcionais por toda essa diversidade. Como os da trabalhadora equatoriana com quem conversei e que limpava meu quarto no College Hall daUniversidadedeLondres,ondefiqueihospedado. Doreen contou sobre uma colombiana que encontrou no hospital em que esteve internada para uma cirurgia do braço e que, mesmo depois de residir há um ano na cidade, ainda não falava inglês. Doreen serviu como sua "tradutora" no hospital, e se sentiu muito feliz por isso. Transitar de fato pelas múltiplas territorialidades que, concomitantemente, uma megacidade como Londres oferece, não é tão fácil. Alguns, mais sofridos (e explorados), podem se fechar como forma de autoproteção e sobrevivência; outros, mais privilegiados, se fecham por empáfia, temores infundados e/ou conservadorismo "hereditário" (como se fosse uma herança a ser compulsoriamente preservada).

Esse jogo entre diferenças que o espaço proporciona, intensamente vivido em nossos encontros, foi uma das características da obra e vida de Doreen que mais me marcaram. Encerro, assim, com um relato que fiz logo que me despedi, no nosso último encontro, em Londres, em julho de 2015, e acrescento três fotos, lembranças pessoais que alimentam o lado bom de uma enorme saudade.

O restaurante afegão, de família muçulmana e donos que são vizinhos de Doreen, não vende bebida alcoólica mas aceita que se leve. Compro um bom vinho francês e brindamos o prazer do estar juntos que realimenta o corpo e a alma de uma amizade que perdura e, surpreendentemente, mesmo na efemeridade deste encontro, parece fortalecida com o tempo. Nossa língua também é múltipla, intercalando palavras em inglês, espanhol e francês, as três línguas que Doreen, como poucos intelectuais britânicos multilíngues, domina.

Transitamos por múltiplos espaços, reconstruindo o nosso. Já não se trata apenas de reconhecer o múltiplo, mas de transitar por ele e vivê-lo, e nosso diálogo também viaja pelo mundo: do Podemos espanhol ao Syriza grego, das férias em que estivemos juntos no Lake District e nas lagoas de Jericoacoara aos planos de nossas viagens à Argentina e França no segundo semestre, dos colegas da Open University britânica e da AAG nos Estados Unidos aos da UFF e da UEPG no Brasil, das ações do radicalismo islâmico às conquistas do movimento LGBT, do carinho de nossas irmãs às histórias de meu pai aos quase 90 anos, da alegria da família que comemora o aniversário, na mesa ao lado, ao africano que a parou na rua para mostrar o voo dos pássaros que acabam de chegar da África do Sul para o verão do Norte ... Um pouco como esses pássaros sem fronteiras, mas que também constroem ninhos, festejamos a diferença acolhedora que o estar junto proporciona: voamos pelo mundo, mas nosso ninho continua sendo tenazmente construído nesses fugazes mas ao mesmo tempo profundos momentos em que a mais genuína expressão do sentimento humano de partilha e companheirismo se realiza. 


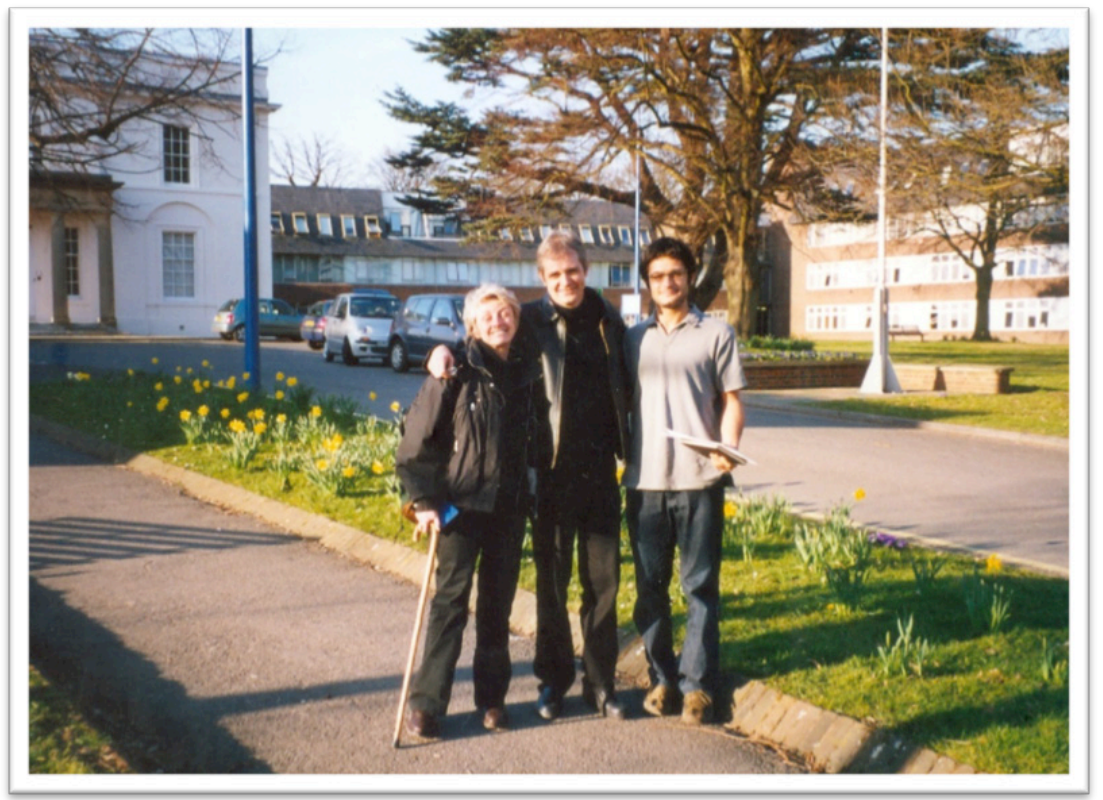

Com Doreen Massey e Arun Saldanha no campus da Open University, em Milton Keynes, 2003
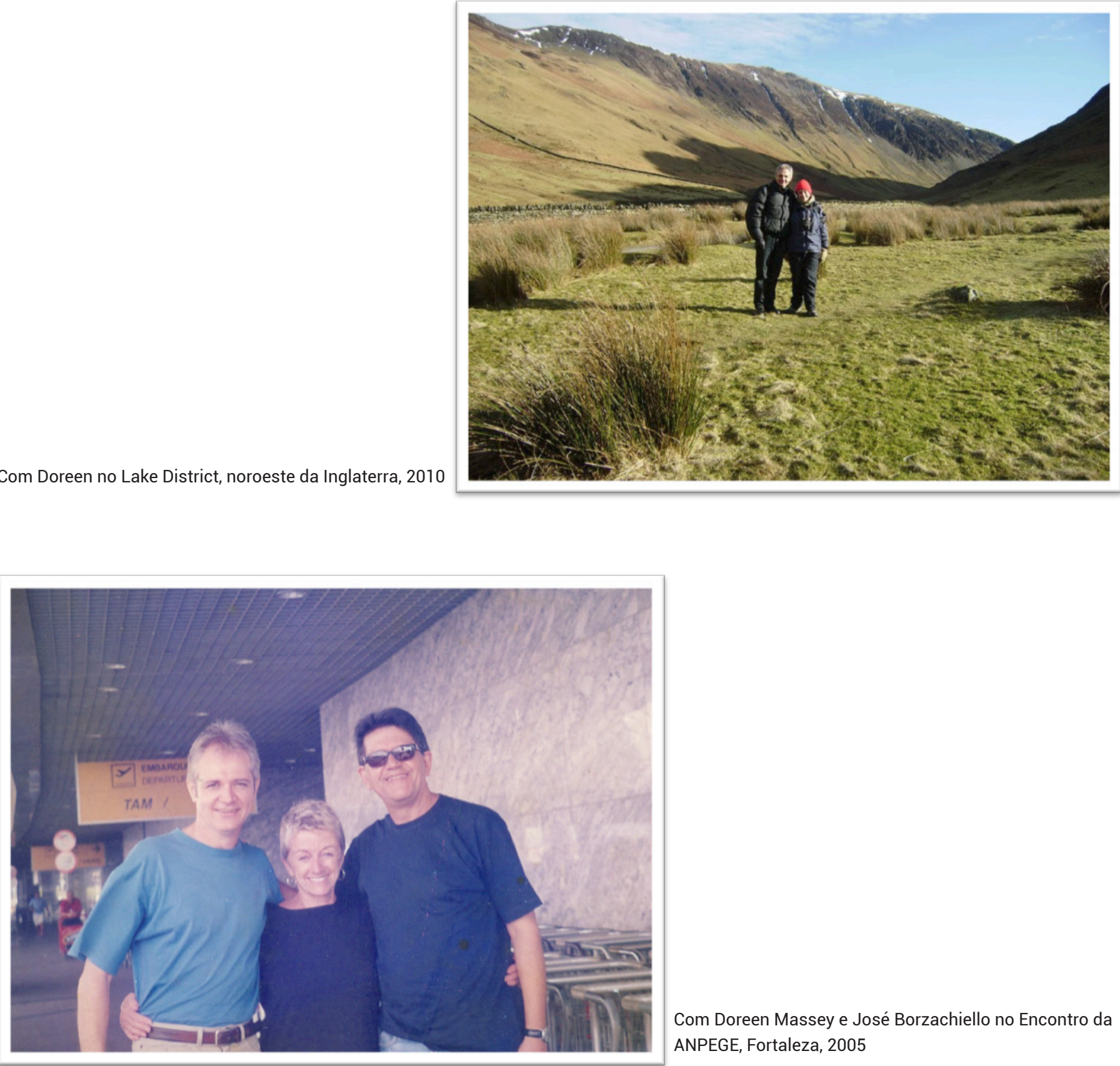

Com Doreen Massey e José Borzachiello no Encontro da ANPEGE, Fortaleza, 2005 


\section{Referências bibliográficas}

ALBET, A. e BENACH, N. 2012. Doreen Massey: un sentido global de lugar. Barcelona: Icaria.

CALLARD, F. 2004. Doreen Massey. In: Hubbard, P. et al. (org.) Key Thinkers on Space and Place. Londres : Routledge. HAESBAERT, R. 2014. Viver no Limite. Rio de Janeiro: Bertrand Brasil.

MASSEY, D. 1981. Regionalismo: alguns problemas atuais. Espaço \& Debates, ano 1, n. 4.

1984. Spatial Divisions of Labour: social structures and the Geography of Production. Basingstoke : Macmillan. (2a. edição em 1995) 1991a. Flexible sexism. Environment and Planning D: Society and Space, v. 9, n. 1. 1991b. Global sense of place. Marxim Today v. 6. 2005. For Space. Londres: Sage (ed. brasileira: « Pelo Espaço » Rio de Janeiro: Bertrand Brasil, 2008) 2007. World City. Londres : Polity.

MASSEY, D.; ALLEN, J. e COCHRANE, A. (org.) 1998. Rethinking the Region. Londres e Nova York: Routledge.

PAINTER, J. e FEATHERSTONE, D. (org.) 2013. Spatial Politics: essays for Doreen Massey. Londres: Wiley-Blackwell.

PHELPS, N. 2008. Spatial Divisions of Labour (1984): Doreen Massey. In: Hubbard, P. et al. (org.) Key Texts in Human Geography. Londres: Sage. 